\title{
Reciclagem de óleos residuais para a produção de sabão no município de Itapetinga-BA
}

\section{Marcondes Viana Silva}

Universidade Estadual do Sudoeste da Bahia mviana@hotmail.com

\section{Meiriane Freitas Dias}

Universidade Estadual do Sudoeste da Bahia meirianefdias@hotmail.com

\section{Priscilla Ferreira Macedo}

Universidade Estadual do Sudoeste da Bahia prisci loirinha@hotmail.com

\section{Silvana Ribeiro Vilas Boas}

Universidade Estadual do Sudoeste da Bahia sil vilasboas@hotmail.com

\section{Poliana Souza Botêlho}

Universidade Estadual do Sudoeste da Bahia botelhops@hotmail.com

Inês Chamel José

Faculdade de Minas

ineschamel@yahoo.com.br

\section{Resumo}

O presente estudo teve como objetivo propor alternativa viável para reciclagem de óleos comestíveis residuais, por meio da produção de sabão utilizando hidrólise alcalina. A matériaprima utilizada para a produção dos sabões foi oriunda de bares e restaurantes do município de Itapetinga, Bahia. Para a produção dos sabões, foram testadas treze metodologias, sendo selecionadas três, com base na textura e aparência do produto. Os sabões obtidos foram, então, submetidos à avaliação de sua qualidade, por meio de questionário aplicado a duas usuárias selecionadas ao acaso em oito lavanderias comunitárias municipais, num total de 16 respondentes. Os atributos avaliados foram consistência, produção de espuma, remoção de sujidades e rendimento. Avaliou-se também a importância da adição de essência e corante aos sabões. Pela análise dos resultados, observou-se que, de maneira geral, os sabões obtidos pelas três metodologias apresentaram boa qualidade, sendo considerada importante a adição de essência e corante aos produtos. Os sabões obtidos pelas metodologias 1 e 2 se sobressaíram ligeiramente em relação ao produto obtido pela metodologia 3. Entretanto, não foi possível uma avaliação conclusiva na definição de uma melhor metodologia para a produção de sabões, considerando a heterogeneidade das respostas, observada devido à baixa escolaridade das respondentes e à sua dificuldade em responder ao questionário. Em face 
disso, nova avaliação da qualidade dos sabões deverá ser conduzida utilizando procedimentos analíticos em laboratório. Porém, a reciclagem de óleos e gorduras residuais mostrou-se viável, e sua utilização deve ser estimulada como ferramenta para preservação ambiental.

Palavras-chave: Preservação ambiental. Reciclagem. Óleos residuais. Sabão.

\title{
Recycling residual oils for the production of soap in the county of Itapetinga-BA
}

\begin{abstract}
This study aims at proposing a viable alternative for the recycling of residual edible oils, through the production of soap using alkaline hydrolysis. The raw material used for the production of the soaps originated from bars and restaurants of the county of Itapetinga, state of Bahia, Brazil. Thirteen methodologies were tested for the production of soap, from which three were selected based on the texture and appearance of the final product. The soaps obtained were, then, submitted to a quality evaluation by means of a questionnaire presented to two users, selected at random in eight municipal community laundry facilities, for a total of 16 respondents. The attributes evaluated were: denseness, foam production, removal of dirt and efficiency. The importance of adding a fragrance and color to the soaps was also evaluated. After analyzing the results, generally, the soaps obtained by the three methodologies presented good quality. The addition of fragrance and color to the products was considered important. The soaps obtained by methodologies 1 and 2 stood out slightly compared to the product obtained by methodology 3 . However, a conclusive evaluation for the definition of the best methodology for the production of soap was not possible due to the heterogeneity of the answers, which was evident due the low educational level of the respondents and their difficulty in answering the questionnaire. Therefore, a new evaluation of the quality of the products will have to be conducted using analytical procedures in the laboratory. However, recycling of residual oils and fats proved viable and its use should be encouraged as a tool for environmental protection.
\end{abstract}

Keywords: Environmental protection. Recycling. Residual oils. Soap.

\section{INTRODUÇÃO}

O consumo de alimentos fritos e pré-fritos tem aumentado nos últimos anos, resultando no aumento da produção de óleos residuais. Admite-se, por exemplo, que 100 toneladas de óleos e gorduras residuais são produzidas por mês na região metropolitana de Curitiba. Esse resíduo é, geralmente, descartado diretamente no esgoto doméstico, acarretando a contaminação ambiental, embora parte de seu volume seja aproveitado para 
produção de sabão, produção de massa de vidraceiro, incorporação na ração animal e, mais recentemente, produção de biodiesel (COSTA NETO et al., 2000).

De acordo com a Oil World, a produção de óleos vegetais no Brasil é estimada em nove bilhões de litros por ano, sendo um terço desse volume destinado à produção de óleos comestíveis. Considerando o volume de óleos residuais coletados no Brasil, tem-se menos de $1 \%$ do total produzido, isto é, seis e meio milhões de litros de óleos usados (MARCONDES, 2010). Mais de 200 milhões de litros de óleos usados são descartados nos rios e lagos anualmente, danificando, assim, o meio ambiente (GAMBOA, 2010). Hoje, o óleo é o maior poluidor de águas doces e salgadas das regiões mais adensadas do Brasil (MARCONDES, 2010).

A poluição e suas consequências são amplamente divulgadas. Entretanto, o conceito de poluição é definido e estabelecido por legislação de acordo com o limite de lançamento de efluentes no meio ambiente. A resolução no 357/05 do Conselho Nacional do Meio Ambiente - CONAMA (BRASIL, 2005a), em seu artigo 34, estabelece as condições e os padrões de lançamento de poluentes nos corpos hídricos, determinando um limite máximo para gorduras de origem vegetal e animal de $50 \mathrm{mg} \cdot \mathrm{L}^{-1}$.

A insolubilidade dos óleos em água e sua menor densidade resultam numa barreira que dificulta a entrada de luz e a oxigenação da água, comprometendo, desse modo, a cadeia alimentar aquática. Além de gerar graves problemas de higiene e odor desagradável, podem causar o entupimento da rede de esgoto, bem como o mau funcionamento das estações de tratamento. Para retirar o óleo e desentupir, são empregados produtos químicos de elevada toxidez, criando, portanto, uma cadeia nociva (SUDHIR et al., 2007). Descartar óleo ou outros resíduos no meio ambiente, de acordo com a Lei Ambiental Federal n ${ }^{\circ}$ 9605/98 (BRASIL, 1998), é considerado crime ambiental sob pena de reclusão, desde que resulte ou possa resultar em danos à saúde humana, ou que provoque a mortandade de animais ou a destruição significativa da flora.

A busca por alternativas relativas à gestão de poluentes e redução de impactos ambientais é um dever social, pois todo ser humano é parte integrante da natureza e, assim, torna-se responsável por sua preservação.

Vários projetos de reciclagem têm sido bem-sucedidos no Brasil. Atualmente, a reciclagem de resíduos agrícolas e agroindustriais vem ganhando espaço cada vez maior, não simplesmente porque os resíduos representam matérias-primas de baixo custo, mas, 
principalmente, porque os efeitos da degradação ambiental decorrente de atividades industriais e urbanas estão atingindo níveis cada vez mais preocupantes (COSTA NETO et al., 2000).

Assim, objetivou-se neste estudo propor alternativa viável para reciclagem de óleos comestíveis residuais, por meio da fabricação de sabão, com base em critérios técnicos, ambientais, sociais e econômicos, contribuindo para a diminuição do impacto ambiental causado pelo descarte indevido desses resíduos.

\section{MATERIAL E MÉTODOS}

O presente estudo foi conduzido no laboratório do Núcleo de Estudos em Ciências de Alimentos (NECAL) do Departamento de Estudos Básicos e Instrumentais (DEBI) da Universidade Estadual do Sudoeste da Bahia (UESB). As análises químicas da matéria-prima, o processamento dos sabões, bem como a avaliação de sua qualidade foram realizados no período de abril a dezembro de 2010 .

\section{Obtenção e Caracterização Química da Matéria-Prima}

A matéria-prima utilizada para a produção dos sabões foi oriunda de bares e restaurantes do município de Itapetinga - Bahia, sendo eles previamente cadastrados no programa de reciclagem de óleos e gorduras residuais da UESB. Os óleos comestíveis residuais foram coletados em baldes plásticos com tampa e conduzidos ao laboratório, onde foram filtrados em tecido tipo gaze e armazenados em baldes plásticos com capacidade para 60 litros. Procedeu-se a avaliação química da matéria-prima por meio das determinações do índice de acidez, índice de iodo (teste de Wijs) e índice de saponificação, conforme os procedimentos descritos a seguir.

Índice de Acidez - A mistura reacional foi realizada em frasco Erlenmeyer de $125 \mathrm{~mL}$ pela adição de 2 g de amostra, $25 \mathrm{~mL}$ de solução éter-álcool (2:1) e duas gotas de fenolftaleína utilizada como indicador. A mistura foi titulada com solução aquosa de $\mathrm{NaOH} 0,1$ mol. $\mathrm{L}^{-1}$, e os resultados foram expressos em porcentagem de ácido oleico, conforme procedimento descrito em Métodos Físico-Químicos para Análise de Alimentos (INSTITUTO ADOLFO LUTZ, 2008). 
Índice de Iodo pelo Método de Wijs - O índice de iodo foi determinado utilizando-se o método de Wijs, recomendado pela American Oil Chemist's Society - AOCS (2009). O teste avalia o grau de insaturação do óleo pela adição de iodo em excesso à amostra, sendo a quantidade de iodo livre determinada pela titulação com solução padrão de tiossulfato de sódio $\left(\mathrm{Na}_{2} \mathrm{~S}_{2} \mathrm{O}_{3}\right)$ 0,1 mol. $\mathrm{L}^{-1}$ e comparada com o branco (isento de óleo). O resultado foi expresso como o número de gramas de iodo absorvido por $100,0 \mathrm{~g}$ da amostra.

Índice de Saponificação - Na determinação do índice de saponificação, adotou-se a metodologia recomendada pela American Oil Chemist's Society - AOCS (2009). No método, a gordura é saponificada sob refluxo com uma solução de hidróxido de potássio e álcool etílico por 30 minutos, sendo o excesso de hidróxido de potássio determinado por titulação com uma solução padrão de ácido clorídrico utilizando fenolftaleína como indicador. Os resultados foram expressos em número de miligramas de hidróxido de potássio necessário para saponificar $1,0 \mathrm{~g}$ da amostra.

\section{Processamento dos Sabões}

Inicialmente, foram testadas treze metodologias para produção de sabões a partir de óleo comestível residual, oriundas de livros, revistas e páginas eletrônicas (sites). Dessas, selecionaram-se as três descritas a seguir, com base na textura e aparência dos produtos. Durante o processo de obtenção dos sabões, os manipuladores utilizaram luvas de borracha, óculos de proteção e roupas adequadas.

Metodologia 1 - Em recipiente plástico, foram adicionados, para cada $1000 \mathrm{~mL}$ de óleo, 400 $\mathrm{mL}$ de solução aquosa de hidróxido de sódio $50 \%(\mathrm{~m} / \mathrm{v})$ a $60{ }^{\circ} \mathrm{C}$ e $40 \mathrm{~mL}$ de amaciante de roupas. Com auxílio de uma colher de pau, a mistura foi homogeneizada durante 20 minutos. Posteriormente, foram acrescidos $8 \mathrm{~mL}$ de óleo essencial. A mistura foi, então, transferida para formas plásticas e desenformada após 24 horas, sendo mantida à temperatura ambiente por 15 dias. Finalmente, as amostras foram acondicionadas em película de PVC e revestidas com celofane de coloração verde, sendo identificadas como sabão verde.

Metodologia 2 - Em recipiente plástico, foram adicionados, para cada $1000 \mathrm{~mL}$ de óleo, 500 $\mathrm{mL}$ de solução aquosa de hidróxido de sódio $50 \%(\mathrm{~m} / \mathrm{v})$ a $60{ }^{\circ} \mathrm{C}$ e $12,5 \mathrm{~g}$ de sabão em pó. Com auxílio de uma colher de pau, a mistura foi homogeneizada durante 20 minutos. Posteriormente, foram acrescidos $8 \mathrm{~mL}$ de óleo essencial. A mistura foi, então, transferida 
para formas plásticas e desenformada após 24 horas, sendo mantida à temperatura ambiente por 15 dias. Finalmente, as amostras foram acondicionadas em película de PVC e revestidas em celofane de coloração azul, sendo identificadas como sabão azul.

Metodologia 3 - Em recipiente plástico, foram adicionados, para cada $1000 \mathrm{~mL}$ de óleo, 500 $\mathrm{mL}$ de solução aquosa de hidróxido de sódio $50 \%(\mathrm{~m} / \mathrm{v})$ a $60{ }^{\circ} \mathrm{C}$ e $250 \mathrm{~mL}$ de solução aquosa de lauril sulfato de sódio $20 \%(\mathrm{~m} / \mathrm{v})$. Com auxílio de uma colher de pau, a mistura foi homogeneizada durante 20 minutos. Posteriormente, foram acrescidos $8 \mathrm{~mL}$ de óleo essencial. A mistura foi, então, transferida para formas plásticas e desenformada após 24 horas, sendo mantida à temperatura ambiente por 15 dias. Finalmente, as amostras foram acondicionadas em película de PVC e revestidas em celofane de coloração rosa, sendo identificadas como sabão rosa.

\section{Determinação do pH dos Sabões}

Em tubo de ensaio, foi homogeneizado, até completa dissolução, $1 \mathrm{~g}$ de amostra em 5 $\mathrm{mL}$ de água. Posteriormente, foi introduzida uma fita indicadora universal de $\mathrm{pH}$, Merck, na faixa de leitura de 0 a 14 (ALLINGER et al., 1985). Esse procedimento foi realizado imediatamente após o processamento dos sabões e ao final de 15 dias.

\section{Avaliação da Qualidade dos Sabões}

Nesta etapa foram cadastradas oito lavanderias comunitárias com o apoio da Secretaria Municipal de Ação Social do município de Itapetinga. De cada lavanderia foram selecionadas, ao acaso, duas usuárias, que receberam os sabões obtidos pelas três metodologias em teste acompanhados de um questionário para avaliação da qualidade dos produtos. Com o questionário pretendeu-se coletar informações relativas aos atributos: consistência, produção de espuma, remoção de sujidades, rendimento, comparação com outros sabões e importância da adição de essência e corante ao sabão. Os questionários foram recolhidos no dia seguinte, sendo, então, realizadas a apuração e a análise dos dados.

\section{RESULTADOS E ANÁLISE}

Os resultados obtidos, relativos à caracterização química do óleo comestível residual, matéria-prima destinada à produção dos sabões, estão apresentados na Tabela 1. Pôde-se 
observar que a matéria-prima utilizada estava imprópria para o consumo humano, apresentando um índice de acidez de $4,10 \mathrm{mg} \mathrm{KOH} . \mathrm{g}^{-1}$, valor muito superior ao máximo estabelecido pela Agência Nacional de Vigilância Sanitária (ANVISA) para óleos vegetais refinados, que é 0,6 mg KOH.g ${ }^{-1}$ (BRASIL, 2005b).

Tabela 1 - Caracterização química do óleo residual destinado à produção dos sabões.

\begin{tabular}{|c|c|}
\hline Análise & Valores obtidos \\
\hline Índice de acidez (mg KOH.g ${ }^{-1}$ ) & 4,10 \\
\hline Índice de iodo - Método de Wijs (g I.100 g $\mathrm{g}^{-1}$ ) & 62,15 \\
\hline Índice de saponificação (mg KOH.g $\left.{ }^{-1}\right)$ & 15,84 \\
\hline
\end{tabular}

A legislação brasileira, entretanto, não estabelece limites para os valores de índice de iodo e índice de saponificação de óleo vegetal. O índice de iodo obtido na análise do óleo residual a ser utilizado na produção dos sabões foi $62,15 \mathrm{~g} \mathrm{I} 100 \mathrm{~g}^{-1}$, valor inferior à faixa característica para óleo de soja, que é 124 a $139 \mathrm{~g} \mathrm{I}^{100} \mathrm{~g}^{-1}$ (CODEX ALIMENTARIUS, 2005), indicando que houve oxidação de ácidos graxos insaturados da amostra, o que é indesejável para o consumo humano. Para o índice de saponificação, obteve-se $15,84 \mathrm{mg}$ $\mathrm{KOH} . \mathrm{g}^{-1}$, sendo também um valor muito abaixo da faixa de valores característicos para óleo de soja, que é de 189 a $195 \mathrm{mg} \mathrm{KOH.g}{ }^{-1}$ (CODEX ALIMENTARIUS, 2005). Esse índice é uma indicação da média da massa molar dos ácidos graxos, isto é, da quantidade relativa de ácidos graxos de alta e baixa massa molar.

Porém, a esse material de baixa qualidade pode ser agregado valor, transformando-o em um produto útil para uso doméstico, contribuindo, assim, para preservação do meio ambiente.

Na Tabela 2, são apresentados os valores de $\mathrm{pH}$ dos sabões, obtidos imediatamente após o seu processamento e ao final de 15 dias. Observou-se que houve redução do $\mathrm{pH}$ em todas as amostras, indicando que o processo de hidrólise dos triacilgliceróis continua após o processamento dos sabões, ocorrendo consumo de hidróxido de sódio. Os valores de $\mathrm{pH}$ dos produtos em teste foram superiores aos de algumas marcas comerciais analisadas, identificadas como X (pH 10,2), Y (pH 9,8) e Z (pH 10), cujo pH médio foi 10. 
Tabela 2 - Valores de pH dos sabões, obtidos imediatamente após o processamento e ao final de 15 dias.

\begin{tabular}{lcc}
\hline Produto & pH inicial & pH após 15 dias \\
\hline Metodologia 1 & 14 & 12 \\
Metodologia 2 & 14 & 11 \\
Metodologia 3 & 14 & 12 \\
\hline
\end{tabular}

Almeida et al. (2011) obtiveram produtos com valores de $\mathrm{pH}$ entre 9 e 10, embora tenham utilizado ácido clorídrico para a redução do pH. Já Volochtchuk et al. (2000) avaliaram o pH de 68 marcas de sabões com o objetivo de verificar o efeito do $\mathrm{pH}$ sobre a pele humana, constatando que, dos 30 sabões em barra, 94,34\% apresentaram valores entre 9 e 10. De acordo com Friedman e Wolf (1996) e Effendy e Maibach (1996), entre os efeitos indesejáveis dos produtos de limpeza sobre a pele, o $\mathrm{pH}$ alcalino é o principal responsável pelo potencial irritante e desidratante da pele.

Os resultados obtidos no teste de avaliação de qualidade dos sabões, produzidos pelas três metodologias em teste, estão apresentados nas Figuras 1, 2, 3, 4 e 5, relativas, respectivamente, à consistência, à produção de espuma, à remoção de sujidades, ao rendimento e à comparação desses sabões com aqueles normalmente utilizados, disponíveis comercialmente. Os resultados constituem respostas de 16 usuárias de lavanderias comunitárias do município de Itapetinga.

Na Figura 1, é apresentada a distribuição das opiniões das respondentes quanto à consistência dos sabões obtidos pelas três metodologias em teste. A consistência não foi bem avaliada pelas respondentes, pois se observou grande divergência de opiniões, impossibilitando definir qual das metodologias resultou em um produto de consistência satisfatória. A dificuldade de avaliação dessa característica talvez possa ser justificada pela falta de compreensão do significado dessa característica devido à baixa escolaridade das respondentes que, inclusive, precisaram de ajuda para responder ao questionário. 


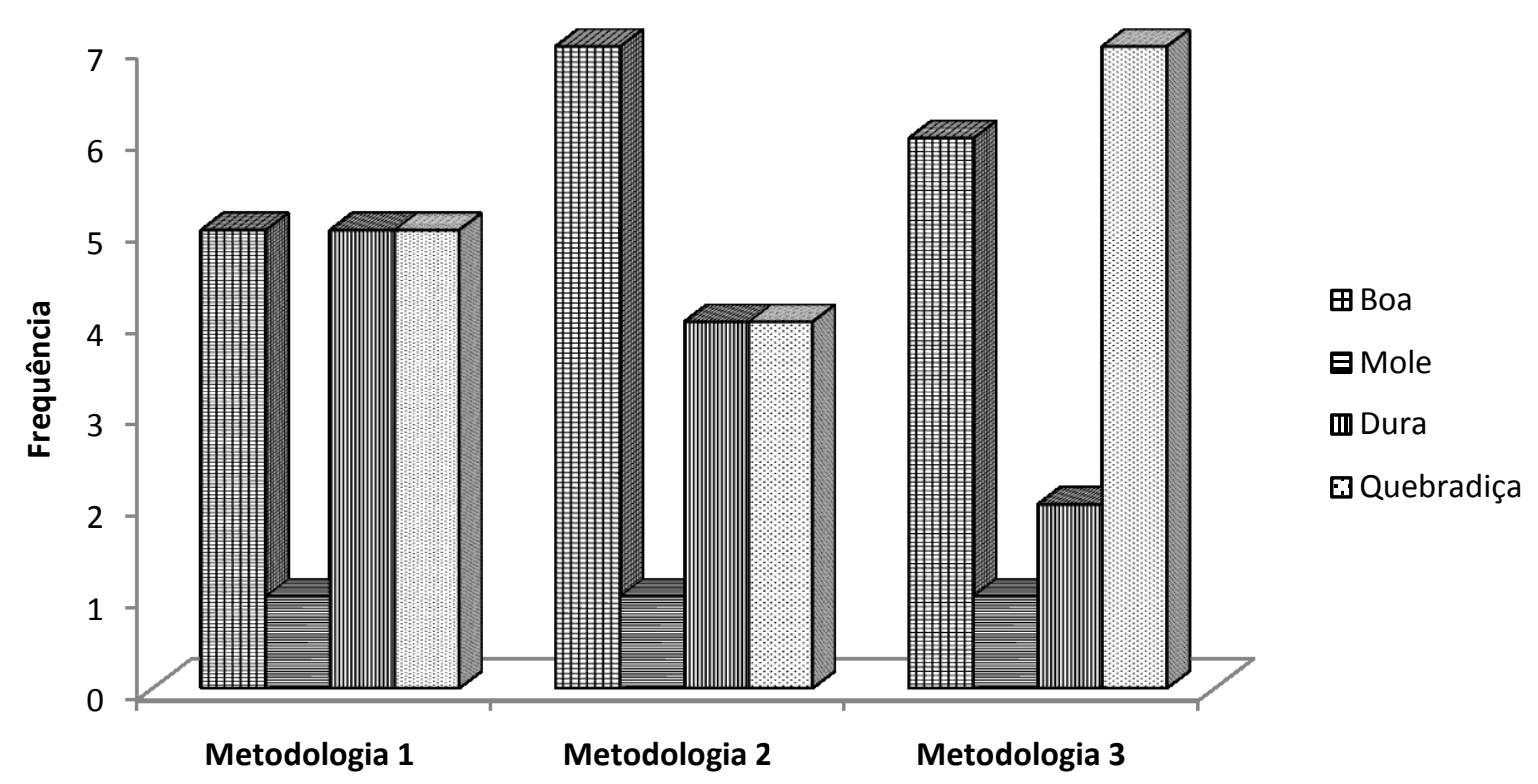

Figura 1 - Distribuição das opiniões das respondentes quanto à consistência dos sabões obtidos pelas três metodologias em teste.

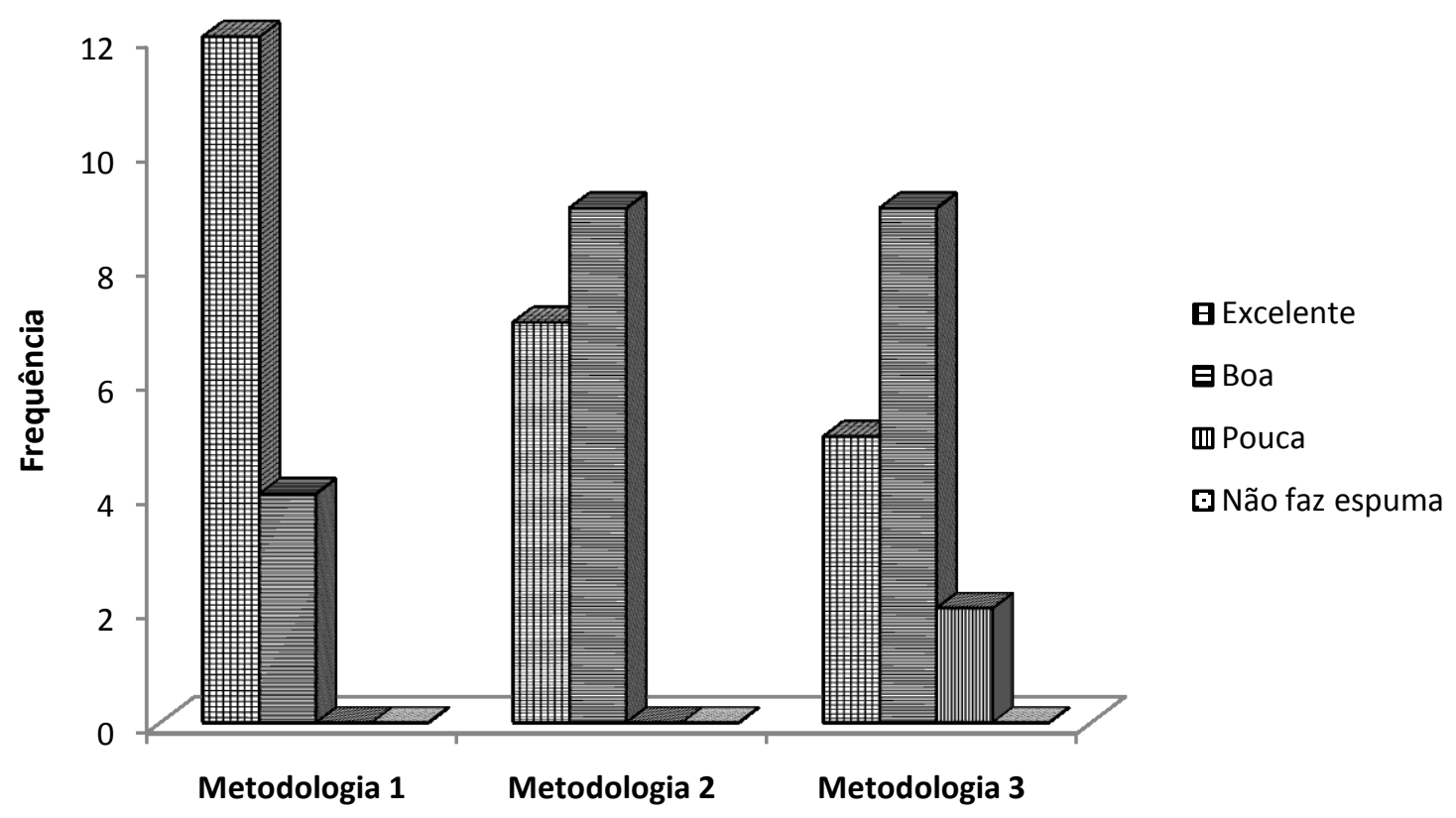

Figura 2 - Distribuição das opiniões das respondentes quanto à produção de espuma pelos sabões obtidos utilizando as três metodologias em teste.

A distribuição das opiniões das respondentes quanto à produção de espuma pelos sabões, obtidos utilizando as três metodologias em teste, é apresentada na Figura 2. Essa característica de qualidade, bem como as demais descritas a seguir, foi mais bem avaliada do

(c) (7) Esta obra está licenciada sob uma Licença Creative Commons. 
que a consistência dos produtos. Para o sabão obtido pela metodologia 1, 12 das 16 respondentes classificaram a sua produção de espuma como excelente e, as demais, a acharam boa. Para a metodologia 2, também a totalidade das respondentes classificou a produção de espuma como excelente e boa, sendo que sete respondentes a avaliaram como excelente e nove, como boa. Já a produção de espuma pelo sabão obtido pela metodologia 3 foi avaliada como excelente por 5 respondentes, como boa por nove, e apenas duas delas consideraram ser pouca a produção de espuma.

Os resultados apresentados na Figura 3 são relativos à capacidade de remoção de sujidades dos sabões obtidos pelas três metodologias em teste. Os sabões produzidos pelas metodologias 1, 2 e 3 foram avaliados como excelente por 6, 8 e 4 respondentes e como apresentando boa remoção de sujidades por 9, 7 e 10 respondentes, respectivamente. Nenhum dos produtos foi considerado ruim com relação a esse atributo de qualidade, porém, os produtos obtidos pelas metodologias 1 e 2 foram avaliados como regular por uma respondente e o produto obtido pela metodologia 3 foi considerado ruim por duas delas. Esses resultados indicam uma ligeira superioridade do produto obtido pela metodologia 2 em relação ao obtido pela metodologia 1 , sendo ambos melhor avaliados que o produto obtido pela metodologia 3 . O produto obtido pela metodologia 2 apresentava em sua formulação sabão em pó, o que pode justificar sua superioridade, uma vez que esse constituinte, obtido comercialmente, contém em sua formulação componentes que conferem melhor detergência.

O produto obtido pela metodologia 3, comparativamente aos demais em estudo, apresentou-se de qualidade inferior no que se refere à produção de espuma e remoção de sujidades. Porém, sua formulação contém lauril sulfato de sódio, ingrediente que confere poder de formação de espuma e detergência.

Segundo Bittencourt Filha et al. (1999), apesar de não haver necessariamente relação entre a capacidade de formação de espuma e a detergência (capacidade de limpar) de um sabão ou detergente, existe uma tendência dos consumidores em associar a formação de espuma com alta capacidade detergente. 


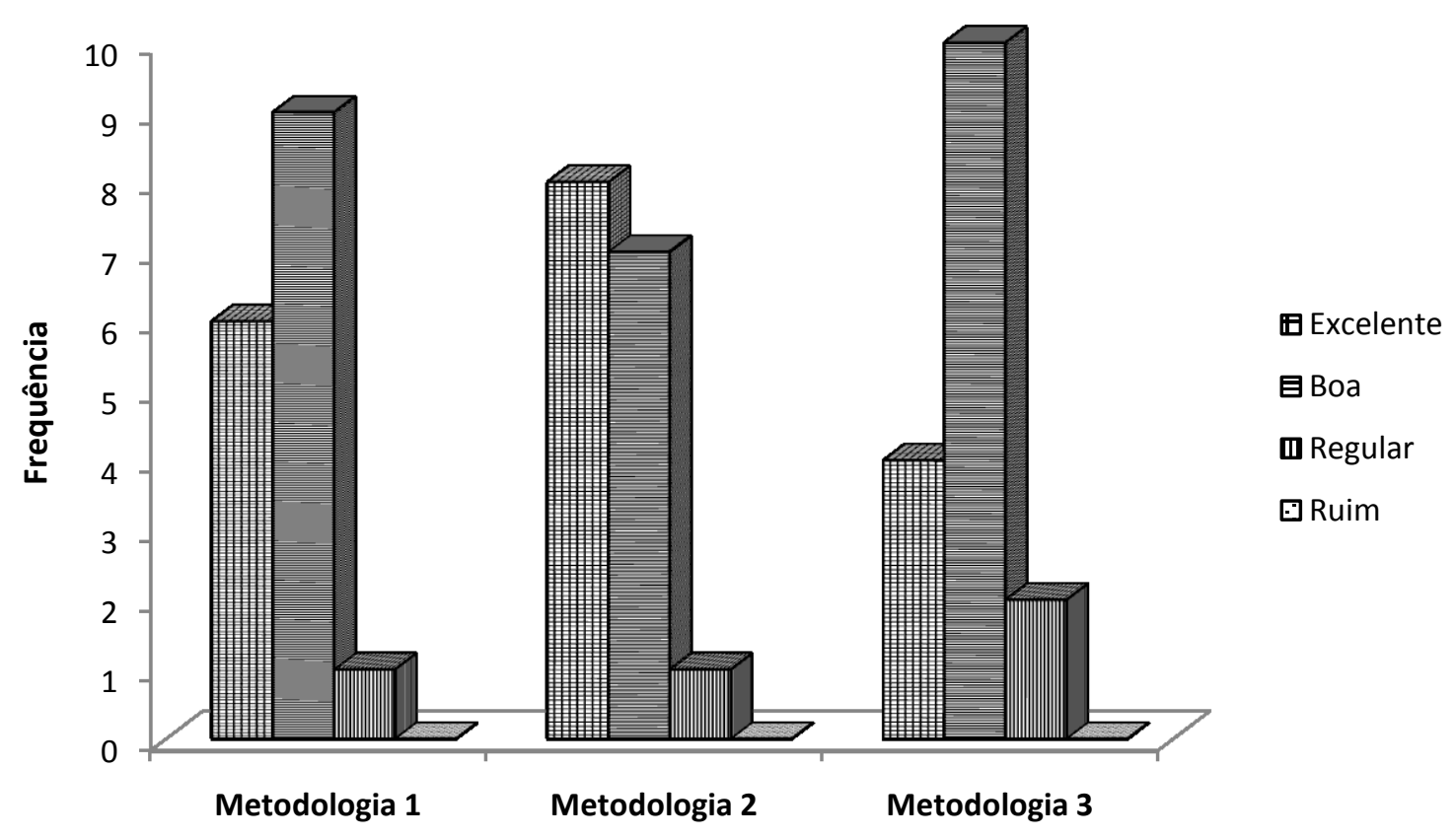

Figura 3 - Distribuição das opiniões das respondentes quanto à capacidade de remoção de sujidades dos sabões obtidos pelas três metodologias em teste.

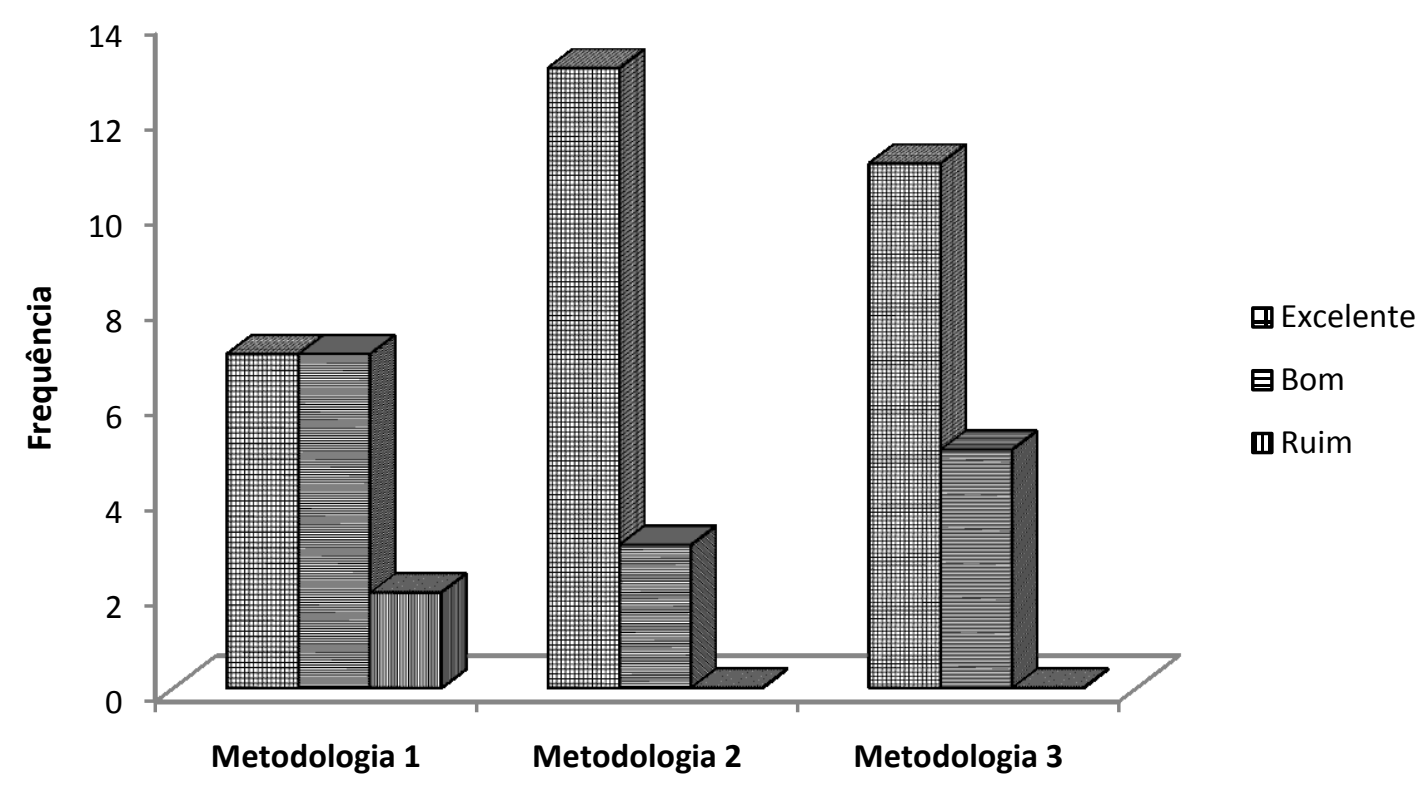

Figura 4 - Distribuição das opiniões das respondentes quanto ao rendimento dos sabões obtidos pelas três metodologias em teste.

Esta obra está licenciada sob uma Licença Creative Commons. 
$\mathrm{Na}$ Figura 4, é apresentada a distribuição das opiniões das respondentes quanto ao rendimento dos sabões obtidos pelas três metodologias em teste. $\mathrm{Na}$ avaliação do produto obtido pela metodologia 1 , duas respondentes o consideraram ruim, sete o avaliaram como apresentando bom rendimento e sete, como excelente. O produto obtido pela metodologia 2 foi avaliado como apresentando excelente e bom rendimento por 13 e três respondentes, respectivamente. Já o sabão obtido pela metodologia 3 foi avaliado por 11 respondentes como apresentando excelente rendimento e bom rendimento por cinco delas. Assim, no que se refere a esse atributo, o sabão obtido pela metodologia 2 mostrou-se ligeiramente superior em relação aos demais.

A comparação entre a qualidade global dos sabões obtidos pelas três metodologias em teste e a qualidade de produtos similares encontrados comercialmente é apresentada na Figura 5. O sabão obtido pela metodologia 1 foi o mais bem avaliado, já que 14 respondentes o acharam de qualidade igual ou superior aos produtos encontrados no mercado, apesar de duas respondentes o considerarem inferior. O produto obtido pela metodologia 2 foi avaliado por 11 respondentes como apresentando qualidade igual ou superior aos produtos encontrados no mercado, porém, cinco delas o classificaram como de qualidade inferior. Já o produto obtido pela metodologia 3 foi avaliado por nove respondentes como de qualidade igual ou superior e por sete delas como de qualidade inferior em comparação aos produtos comerciais.

Alberici e Pontes (2004) também produziram um sabão utilizando óleos e gorduras residuais, obtendo um produto de consistência firme, espumante e eficiente em limpeza de roupas e louças. Entretanto, esses autores não mencionaram como essas características foram avaliadas. Já Baldasso et al. (2010) testaram três formulações de sabão utilizando óleo residual de fritura, designando-os sabão tradicional, de milho e de abacate, sendo respectivamente adicionadas aos dois últimos farinha de milho e massa de abacate. Os produtos foram avaliados quanto a diferentes características, por meio de questionário aplicado a 10 pessoas, sendo o sabão tradicional o que apresentou melhor qualidade.

Pelos resultados apresentados na Figura 6, foi possível observar que as respondentes consideraram ser mais importante a adição de essência do que a adição de corante ao sabão, sendo ambas consideradas importantes. Treze delas relataram ser necessária a adição de essência e três a consideraram desnecessária. Já a adição de corante foi apontada como necessária por 10 respondentes e desnecessária pelas demais. 


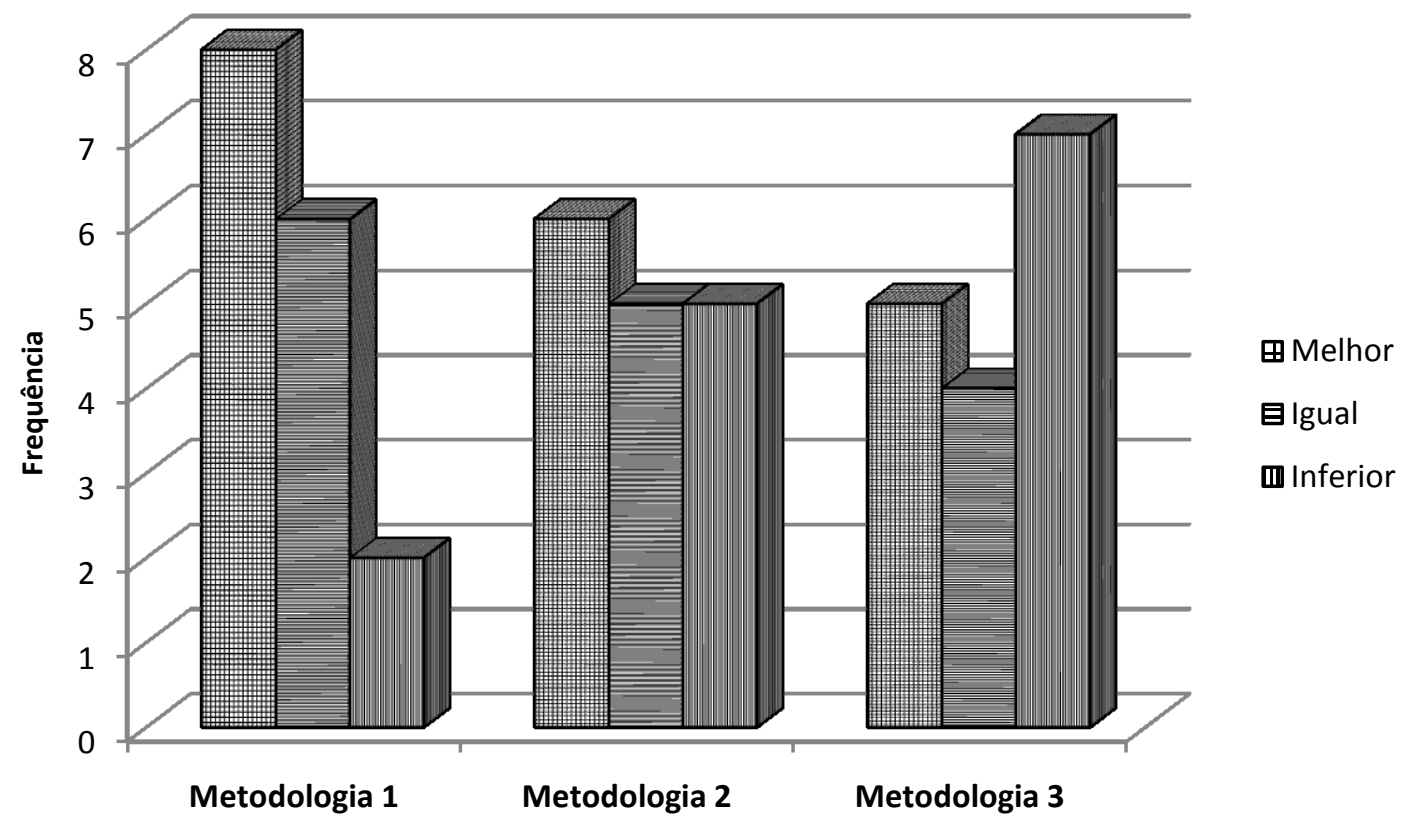

Figura 5 - Distribuição das opiniões das respondentes sobre a qualidade dos sabões obtidos pelas três metodologias em teste em comparação aos produtos similares encontrados comercialmente.
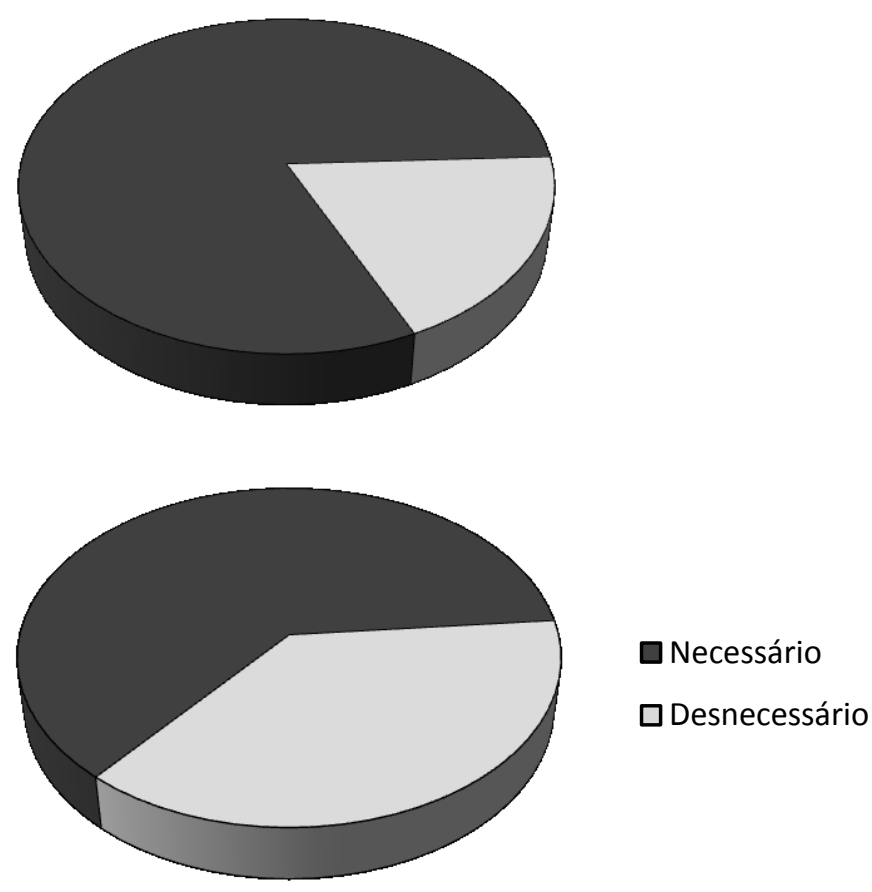

Figura 6 - Opinião das respondentes quando questionadas sobre a importância de: $\mathbf{A}$ - adição de essência ao sabão e $\mathbf{B}$ - adição de corante ao sabão.

Esta obra está licenciada sob uma Licença Creative Commons. 


\section{CONSIDERAÇÕES FINAIS}

Pelos resultados obtidos neste estudo, observou-se ser possível elaborar sabões de boa qualidade a partir de óleos comestíveis residuais, apresentando-se como alternativa viável para minimizar os prejuízos ambientais que essa matéria-prima causa quando descartada no meio ambiente. Entretanto, não foi possível uma avaliação conclusiva na definição de uma melhor metodologia para a produção de sabões, considerando a heterogeneidade das respostas, observada devido à baixa escolaridade das respondentes e à sua dificuldade em responder ao questionário. Em face disso, nova avaliação da qualidade dos sabões deverá ser conduzida utilizando procedimentos analíticos em laboratório.

\section{REFERÊNCIAS}

ALBERICI, R. M.; PONTES, F. F. de. Reciclagem de óleo comestível usado através da fabricação de sabão. Engenharia Ambiental, Espírito Santo do Pinhal, v. 1, n. 1, p. 73-76, 2004.

ALLINGER, N. et al. Química orgânica. Tradução de R. B. de Alencastro, J.S. Peixoto e L.R.N. de Pinho. Rio de Janeiro: Guanabara 2, 1985. p. 173.

ALMEIDA, G. S.; ROCHA, V. K. G.; PARACAMPO, N. E. N. P. Sabão de óleo residual de fritura formulado com infusão de casca de Citrus. In: CONGRESSO BRASILEIRO DE QUÍMICA, 51., out. 2011, São Luiz. Disponível em:

$<$ http://www.abq.org.br/cbq/2011/trabalhos/5/5-857-10119.htm> Acesso em: 03 dez. 2011.

FIRESTONE, D. (Ed.). Official methods and recommended practices of the AOCS: Fats, Oils and Lipid Related Analytical Methods. 6. ed. [S.1.]: AOCS Press, 2009.

BALDASSO, E.; PARADELA, A.L.; HUSSAR, G.J. Reaproveitamento do óleo de fritura na fabricação de sabão. Engenharia Ambiental, Espírito Santo do Pinhal, v. 7, n. 1, p. 216-228, 2010.

BITTENCOURT FILHA, A. M. B.; COSTA, V. G.; BIZZO, H. R. Avaliação da qualidade de detergentes a partir do volume de espuma formado. Química Nova na Escola, São Paulo, v. 1, n. 9, p. 43-45, 1999.

BRASIL. Presidência da República. Casa Civil. Subchefia para Assuntos Jurídicos. Lei N ${ }^{\mathrm{o}}$ 9.605, de 12 de fevereiro de 1998. Dispõe sobre as sanções penais e administrativas derivadas de condutas e atividades lesivas ao meio ambiente, e dá outras providências. Brasília, DF, 12 fev. 1998. Disponível em: <http://www.planalto.gov.br/ccivil_03/leis/L9605.htm> Acesso em: 04 set. 2012. 
BRASIL. Resolução CONAMA n 357 , de 17 de março de 2005. Dispõe sobre a classificação dos corpos de água e diretrizes ambientais para o seu enquadramento, bem como estabelece as condições e padrões de lançamento de efluentes, e dá outras providências. Diário Oficial da União, Brasília, DF, n. 053, 18 mar. 2005a. Seção 1, p. 58-63.

BRASIL. Ministério da Saúde. Agência Nacional de Vigilância Sanitária. Resolução RDC no 270 , de 22 de setembro de 2005. Aprova o regulamento técnico para óleos vegetais, gorduras vegetais e creme vegetal. Diário Oficial da União, Brasília, DF, 23 set. 2005b. Seção1, p. 372- 373 .

CODEX ALIMENTARIUS - Codex standards for named vegetable oils. Roma, FAO/ WHO. Codex Stan 210 (Revisão. 2003-2005).

COSTA NETO, P. R. et al. Produção de biocombustível alternativo ao óleo diesel através da transesterificação de óleo de soja usado em frituras. Química Nova, São Paulo, v. 23, n. 4, p. 531-537, 2000.

EFFENDY, I.; MAIBACH, H. I. Detergent and skin irritation. Clinics in Dermatology, Philadelphia, v. 14, n. 1, p. 15-21, 1996.

FRIEDMAN, M.; WOLF, R. Chemistry of soaps and detergents various types of commercial products and their ingredients. Clinics in Dermatology, Philadelphia, v. 14, n. 1, p. 7-13, 1996.

GAMBOA, T. Do óleo de cozinha ao biodiesel. Ciência e Vida, Rio de Janeiro, ed. 066, dez. 2006. Disponível em:

$<$ http://www.olharvital.ufrj.br/2006/index.php?id_edicao=066\&codigo=2 $>$ Acesso em: 19 jun. 2010.

INSTITUTO ADOLFO LUTZ. Métodos físico-químicos para análises de alimentos. 4. ed. São Paulo: 2008. 1020 p.

MARCONDES, C. Reciclagem do óleo. ECÓLEO - Associação Brasileira para Sensibilização, Coleta, Reaproveitamento e Reciclagem de Resíduos de Óleo Comestível. Disponível em: <http://www.ecoleo.org.br/reciclagem.html> Acesso em: 20 set. 2010.

SUDHIR, C. V.; SHARMA, N. Y.; MOHANAN, P. Potential of waste cooking oils as biodiesel feed stock. Emirates Journal for Engineering Research, Al-Ain, v. 12, n. 3, p. 6975, 2007.

VOLOCHTCHUK, O. M. et al. Variações do pH dos sabonetes e indicações para sua utilização na pele normal e na pele doente. Anais Brasileiros de Dermatologia, Rio de Janeiro, v. 75, n. 6, p. 697-703, 2000. 